\title{
ESPACIOS INTERNODALES EN PATAGONIA SEPTENTRIONAL: BIOGEOGRAFÍA, INFORMACIÓN Y MECANISMOS SOCIALES DE INTERACCIÓN
}

\author{
INTER-NODAL SPACES IN NORTHERN PATAGONIA: BIOGEOGRAPHY, INFORMATION, AND SOCIAL \\ MECHANISMS OF INTERACTION
}

Ramiro Barberena ${ }^{1}$, Guadalupe Romero Villanueva ${ }^{2}$, Gustavo Lucero ${ }^{3}$, María Victoria Fernández ${ }^{4}$, Agustina A. Rughini ${ }^{5}$ Paula Sosa ${ }^{3}$

\begin{abstract}
Resumen
El análisis de los espacios internodales en escala arqueológica ofrece un marco adecuado para la integración de preguntas generadas desde distintos ámbitos teóricos, con un gran potencial de complementariedad. El objetivo de este trabajo es evaluar, desde una perspectiva biogeográfica, el rol desempeñado por los espacios internodales en la dinámica de interacción social intergrupal en Patagonia septentrional. En primer lugar, presentamos los lineamientos teórico-metodológicos que guían nuestra propuesta, en la cual la biogeografía constituye el marco de referencia para identificar distintos tipos de Ei en la región de estudio. Existe una importante variación geográfica y ecológica en los sectores del paisaje que pueden haber constituido internodos en el pasado, la cual debe ser caracterizada como un primer paso para evaluar su dinámica sociodemográfica. Planteamos que hay dos variables ecológicas claves que establecen la base geográfica de los internodos: a) gradiente de variación en la disponibilidad de recursos; $y$ b) escala espacial de los espacios internodales. En segundo lugar, sobre la base de información en escala etnográfica, describimos en forma muy simple los mecanismos sociales de interacción que regulan el acceso y uso de este tipo de espacios. Con ello, buscamos comenzar a modelar arqueológicamente

la dinámica relacionada al uso de los internodos en Patagonia septentrional. En tercer lugar, exploramos el rol de dos líneas de evidencia que informan sobre interacción social y circulación de información/objetos: las representaciones rupestres y la geoquímica de obsidianas. Para finalizar, reflexionamos sobre el alcance de los aportes generados y proponemos líneas futuras de trabajo que permitirán profundizar la comprensión de la dinámica humana de circulación de información/objetos implementada en el noroeste de Patagonia, así como de las redes de interacción que vincularon grupos de cazadores recolectores en distintas escalas espaciales.
\end{abstract}

Palabras claves: Biogeografía humana - interacción social - distribución de representaciones rupestres - geoquímica de obsidianas - noroeste de Patagonia.

Recibido: marzo 2016. Aceptado: noviembre 2016

\begin{abstract}
The analysis of internodal spaces in archaeological scale offers a frame useful for integrating questions produced from different theoretical stands, which are actually complementary. The goal of this paper is to assess the role of internodal spaces for inter-group interaction in northern Patagonia from a biogeographical perspective.

First, we present the theoretical-methodological frame that guides this proposal.

There is important geographical and ecological variation in those parts of a given landscape that can be considered as internodes during the past, which should be characterized as a first step to assess their socio-demographic dynamics. We suggest that there are two key ecological variables that make up the basis of internodes: a) gradient of ecological variation in resources; b) spatial scale of the internodes. Secondly, based on ethnographic information, we describe in a simple manner the possible social mechanisms of interaction that structure and regulate the access to and circulation across internodes. By using this frame, we intend to model the archaeological dynamics of the human use of internodal areas in northern Patagonia. In third place, we explore the role of two lines of research that may constitute proxies on social interaction and circulation of information/objects in space: rock art and obsidian geochemistry. Finally, we consider the preliminary contribution of this research, suggesting paths for future development of these ideas.
\end{abstract}

Keywords: Human biogeography - social interaction - spatial distribution of rock art - obsidian geochemistry - northwestern Patagonia.

\section{* Introducción y marco de trabajo}

Los estudios de espacios internodales (Ei) en escala arqueológica ofrecen un marco adecuado para la integración de preguntas generadas desde distintos ámbitos teóricos, con un gran potencial de complementariedad. Estos estudios han contribuido a identificar la relevancia de los Ei, generalmente amplios y ubicados entre los nodos poblacionales, para comprender las trayectorias históricas humanas en el largo plazo. Estos avances también han visibilizado problemas metodológicos relacionados con su aplicación debido, en parte, a que dirigen la atención hacia sectores del espacio que predisponen un uso humano intermitente $y$, por ende, en ellos se genera un registro arqueológico de baja densidad (aunque el mismo pueda estar fuertemente concentrado en determinadas localizaciones). Así, el estudio sistemático de estos contextos impone un desafío no solo teórico, sino también metodológico, al enfrentarnos a un registro arqueológico que trasciende al sitio como unidad básica de análisis. Dado este escenario, buscamos estimular esta discusión al aplicar en forma exploratoria este concepto en Patagonia, donde este tipo de prácticas de investigación es usual, así como también desde marcos teóricos alternativos a los que tradicionalmente caracterizan a los estudios internodales.

De esta manera, el objetivo del trabajo es evaluar, desde una perspectiva biogeográfica, el rol desempeñado por los Ei en la dinámica de interacción social intergrupal en el noroeste de Patagonia. Para ello, en primer lugar efectuamos una breve revisión sobre el desarrollo de los estudios internodales; luego, presentamos los lineamientos

1 CONICET, Laboratorio de Paleoecología Humana, Facultad de Ciencias Exactas y Naturales, Universidad Nacional de Cuyo, Mendoza. Padre Jorge Contreras 13oo, 5500, Mendoza, ARGENTINA. Email: ramidus28@gmail.com

2 CONICET, Instituto Nacional de Antropología y Pensamiento Latinoamericano. 3 de Febrero 1378, C1426BJN, Ciudad Autónoma de Buenos Aires, ARGENTINA. Email: guada.romero.arq@gmail

3 Facultad de Ciencias Exactas y Naturales, Universidad Nacional de Cuyo, Mendoza. Padre Jorge Contreras 1300, 5500, Mendoza, ARGENTINA. Email: glucerol8@ gmail.com, psosamodon@gmail.com

4 CONICET, Instituto de Arqueología, Facultad de Filosofía y Letras, Universidad de Buenos Aires. Ciudad Autónoma de Buenos Aires, ARGENTINA. Email: fernandezvicky5@gmail.com

5 Facultad de Filosofía y Letras, Universidad de Buenos Aires. Puán 470, Ciudad Autónoma de Buenos Aires, ARGENTINA. Email: agustinarughini@yahoo.com.ar 
teórico-metodológicos que guían nuestra propuesta, en la cual la biogeografía constituye el marco de referencia para identificar distintos tipos de Ei. Seguidamente, integramos los planteos biogeográficos con información generada en escala etnográfica sobre mecanismos sociales de interacción que regulan el acceso y uso de este tipo de espacios. Con ello, buscamos comenzar a modelar en una escala etnográfica la dinámica relacionada al uso de espacios potencialmente internodales en el noroeste de Patagonia (Provincia del Neuquén, Figura 1). Para Patagonia no se cuenta con indicadores arqueológicos específicos que provean evidencia directa de una u otra forma de uso e interacción social en los espacios contemplados como Ei. Creemos que esto será posible a futuro, en el marco de tratamientos en escala regional que integren múltiples líneas de trabajo y busquen otorgar sentido espacial y demográfico a determinados paisajes arqueológicos. Reconociendo que una evaluación en sentido estricto de las formas de uso humano de los Ei no es posible en función de la información actualmente disponible, exploramos el rol de dos líneas de evidencia que informan sobre interacción social y circulación de información/objetos: las representaciones rupestres y la geoquímica de obsidianas. Para finalizar, reflexionamos sobre el alcance de los aportes generados y proponemos líneas futuras de trabajo que permitirán profundizar la comprensión de la dinámica humana de circulación de información/objetos implementada en el noroeste de Patagonia, así como de las redes de interacción que vincularon grupos de cazadores recolectores en distintas escalas espaciales.

\section{Estudios internodales: un caso de convergencia intelectual}

Los estudios internodales se definen por su foco de análisis en los espacios intermedios con respecto a los "asentamientos relativamente permanentes (escala intrarregional) o regiones con densidades altas de población estable (escala interregional)" (Nielsen 2006:34). Sobre la base de diversos desarrollos a escala mundial, estos estudios toman su forma actual a lo largo de los últimos 15 años aproximadamente. Tradicionalmente desarrollados en la región de los Andes centro sur, hoy constituyen un enfoque distintivo que tiene la virtud de situar la atención sobre un segmento del registro arqueológico que, aunque es espacialmente muy abarcativo, ha sido considerado de relevancia secundaria para la reconstrucción de las secuencias tradicionales de cambio histórico y dinámicas sociales en el espacio (Nielsen 2006; Berenguer y Pimentel 2010). Este notable avance se vio facilitado por las características de los registros etnográficos, etnohistóricos y/o arqueológicos de dicha área de investigación, en su mayoría dotados de una elevada resolución temporal, que ofrecen información con cierto grado de completitud sobre la dinámica social de las interacciones pasadas (Berenguer 2010; Chacama 2010; Knudson et al. 2012; Torres-Rouff et al. 2012, entre otros).

Diversos desarrollos en escala mundial también contribuyeron a delinear un interés por las propiedades del registro arqueológico en los Ei en Patagonia, donde diversos proyectos adoptan una perspectiva guiada por un esquema espacial de nodos y áreas marginales sobre la base de un marco biogeográfico de referencia (Borrero 1994-1995, 2004, 2005; Figuerero Torres y Mengoni Goñalons 2006; Gil 2006; Barberena 2008, 2013; Belardi et al. 2009, 2016; Borrero y Borrazzo 2011). Tomando en cuenta estos aportes, consideramos que el foco actual en los Ei constituye un interesante caso de convergencia intelectual en el cual, desde intereses y preguntas diferentes, se confluye en programas de trabajo con (algunos) supuestos teórico-metodológicos compartidos. Esta confluencia no es aleatoria; por el contrario, pone de manifiesto un estado de madurez de la disciplina que lleva a identificar problemas teórico-metodológicos en común que trascienden los procesos históricos y enfoques dominantes en cada región. Esta situación no resta individualidad a estos distintos aportes, ya que las perspectivas, preguntas y énfasis metodológicos son distintos. Al asimilar en forma crítica los aportes que cada ámbito de trabajo realiza en esta instancia de confluencia, se puede ampliar y robustecer el alcance de los estudios internodales. Consideramos que los Ei definen un campo de trabajo que es relevante a lo largo de todo el espectro de movilidad y complejidad sociopolítica humana. Creemos también que estos conceptos tienen un amplio potencial analítico en distintas escalas temporales, que pueden evidenciar procesos y mecanismos históricos diversos (Bailey 2007), probablemente conectados en forma jerárquica entre sí.

En un marco exploratorio de análisis, buscamos definir nuevas preguntas de investigación que conecten el marco de estudios internodales con los problemas regionales en 


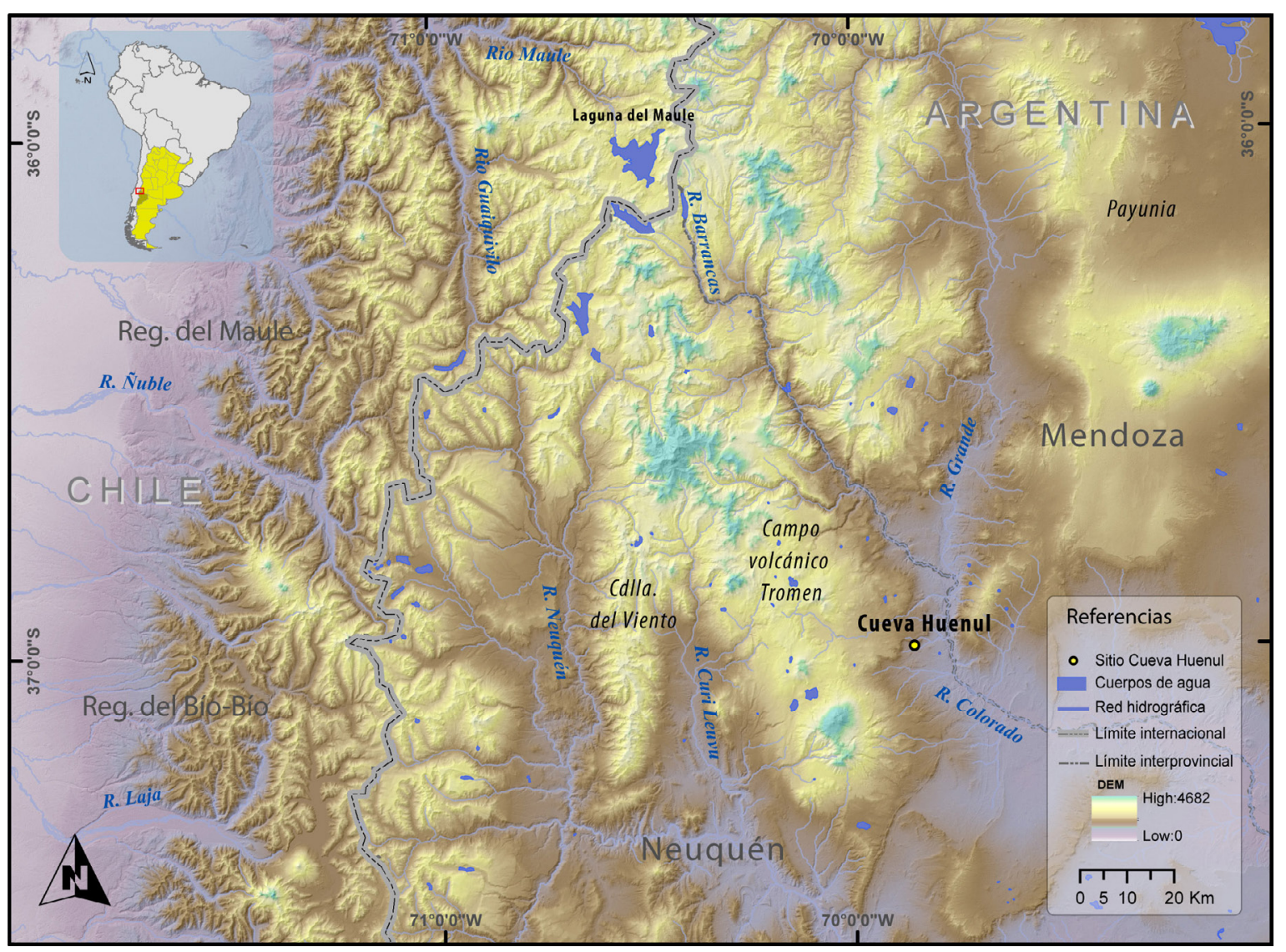

Figura 1. Macrorregión de estudio (norte de la Provincia del Neuquén) e información altitudinal.

la arqueología de Patagonia. Uno de los principales desafíos es hacer operativos los conceptos de nodos e internodos para enfrentar un registro arqueológico formado en el largo plazo y, usualmente, con baja resolución conductual. Es por ello que en este trabajo exploramos el alcance de los Ei para generar preguntas espaciales y temporales sobre la arqueología del noroeste de Patagonia (Figura 1). Desde nuestra perspectiva, la biogeografía constituye una instancia teórica de rango medio, con la capacidad de articular en forma coherente diversas preguntas y líneas de evidencia. Un aspecto clave a evaluar es la relación entre la configuración ecológica del paisaje y la distribución espacial de los nodos e internodos poblacionales. Sostenemos que este marco de referencia contribuirá a situar el análisis de los mecanismos sociales de interacción y la circulación de información en estos espacios.

\section{Internodos en clave biogeográfica}

Existe una importante variación geográfica y ecológica en los sectores del paisaje que pueden haber constituido Ei en el pasado, la cual debe ser caracterizada como un primer paso para evaluar su dinámica sociodemográfica (Borrero 2004; Harcourt 2012; Barberena 2013). Esto resulta particularmente clave cuando se busca incorporar una perspectiva comparativa macrorregional al análisis, ya que debemos partir de un marco que establezca las propiedades de aquellos espacios que buscamos integrar en el mismo. Como primer acercamiento, creemos que hay dos variables ecológicas que establecen la base geográfica de los Ei: a) gradiente de variación en la disponibilidad de recursos (agua, recursos alimentarios), que puede ser gradual o abrupto; $y$ b) escala espacial de los Ei. 
¿Cuál es el gradiente de variación en la distribución de recursos claves para las sociedades humanas? Esto marcará cuál es la magnitud del contraste entre los Ei y los nodos. Las 'zonas de concentración de nutrientes' definidas por Yacobaccio (1994) para diversos ámbitos de la puna, o los principales enclaves costeros del desierto de Atacama (Marquet et al. 2012), ofrecen ejemplos de contrastes abruptos en la disponibilidad de recursos. Por otra parte, los ámbitos de transición entre las provincias fitogeográficas xéricas (Provincia del Monte) y mésicas (provincia patagónica) de Patagonia discutidos aquí ofrecen ejemplos de variación que se expresan en forma más gradual (Páez et al. 2004).

En segundo lugar, debemos evaluar cuál es la escala o el tamaño de los espacios que, potencialmente, pueden haber funcionado como Ei. Los espacios de los Andes centro-sur mencionados arriba son ejemplos de Ei de gran amplitud espacial. Lo mismo puede plantearse para grandes sectores de ambiente xérico de Monte en el este de la Provincia del Neuquén y el sur de Mendoza -campo volcánico La Payunia- (Gil 2006; Barberena 2013). En la discusión de nuestro caso de estudio presentaremos un ejemplo posible de un Ei espacialmente acotado, lo cual abre un conjunto de consideraciones sobre diferentes formas de uso e interacción social. Sintetizando estos planteos, una evaluación de los gradientes de contraste ecológico y las escalas espaciales de los paisajes considerados contribuyen a establecer el perfil geográfico de los potenciales Ei.

\section{* Espacios internodales y mecanismos de INTERACCIÓN: MODELO ETNOGRÁFICO}

Los nodos a nivel espacial o demográfico son aquellos ámbitos donde los grupos humanos residen una mayor parte del tiempo (Borrero y Barberena 2006; Mizoguchi 2009); en oposición, los internodos son ocupados en forma menos intensa y/o recurrente. Sin embargo, la utilización de éstos puede articularse sobre la base de esquemas diversos de organización socioespacial. En este contexto, cabe preguntarse: ¿Cuáles son los mecanismos sociales que estructuran el acceso, circulación y asentamiento en los Ei? Lógicamente, estos mecanismos experimentan cambios a través del tiempo, en relación con las condiciones sociodemográficas imperantes a nivel regional. Evaluar el carácter de estos mecanismos será relevante no solo para una mejor comprensión de la dinámica social en los internodos, sino de los sistemas humanos mayores donde se insertan.

Para comenzar a desentrañar la complejidad de estos mecanismos, proponemos un esquema inicial basado en información en escala etnográfica. Esta información no es utilizada en forma analógica para ser contrastada de manera lineal con la evidencia arqueológica, sino que contribuye a modelar procesos de largo plazo relevantes para nuestro caso (cf. Binford 1977; Dyson-Hudson y Smith 1978; O'Connell 2006); específicamente, la dinámica y diversidad de las interacciones entre poblaciones relacionadas al uso común de territorios. Utilizamos un continuum que va de menor a mayor control de un espacio por parte de un grupo determinado. Sobre la base de las variables biogeográficas descriptas, planteamos un sencillo modelo que, aunque no sería visible linealmente en el registro arqueológico, genera implicaciones materiales que pueden ser evaluadas mediante un enfoque contextual que integre diversas líneas de evidencia (Figura 2).

En primer lugar, está el caso que podemos denominar 'tierra de nadie', que define regiones de libre uso para cualquier individuo o grupo humano, ya que no presenta normativas sociales que regulen el acceso, circulación y asentamiento. A priori, cabe esperar esta situación en Ei caracterizados por una muy baja productividad ecológica y, posiblemente, amplios a nivel espacial (Figura 2a).

En segundo lugar, utilizamos la categoría de 'espacios y recursos de uso comunal' (common pool resources), que son ámbitos sobre los cuales tienen derecho de acceso y ocupación diversos grupos, aunque a diferencia del caso anterior, esto no aplica a cualquier grupo, ya que el uso está sancionado a nivel social (Eerkens 1999; Bayman y Sullivan 2008; Agrawal 2003). Estos espacios de uso común pueden funcionar en distintas escalas sociales, desde acuerdos generados en el nivel interindividual o interfamiliar, hasta convenios en la escala de distintos Estados-nación (Eerkens 1999). Este tipo de uso regulado y compartido suele ser frecuente en sociedades con un componente pastoril en la subsistencia, particularmente en ámbitos con buena disponibilidad estacional de pasturas (Eerkens 1999: 308), aunque las mismas consideraciones pueden aplicar en contextos con disponibilidad estacional de recursos silvestres. El uso compartido puede 


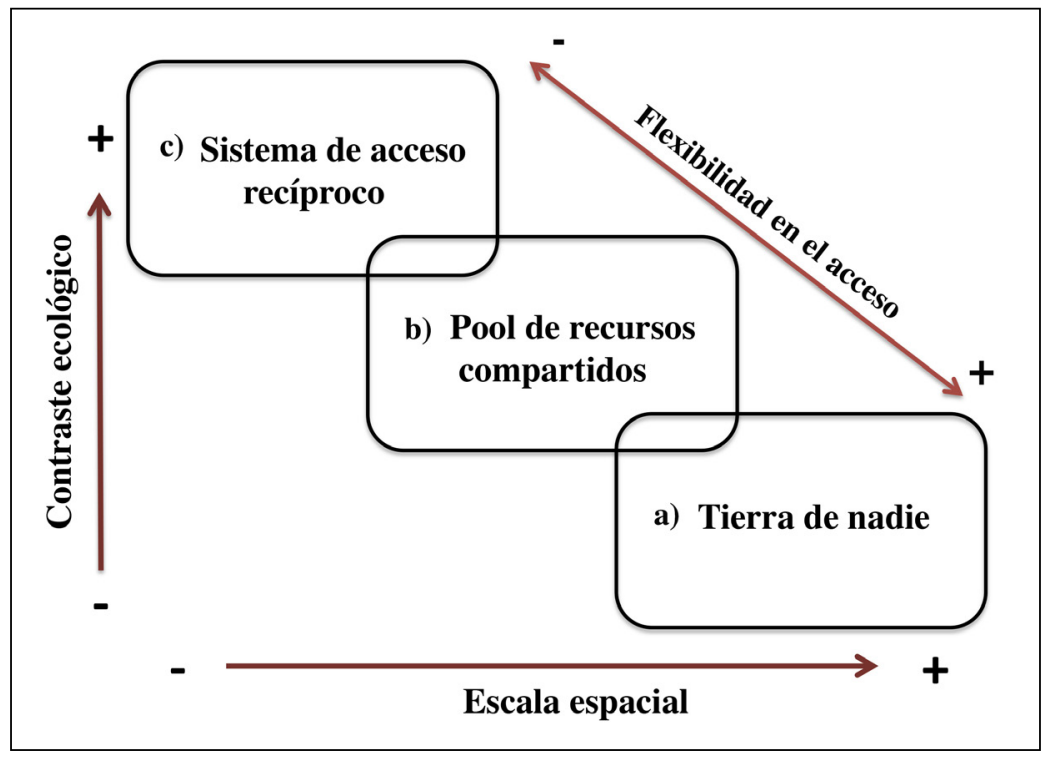

Figura 2. Modelo de base biogeográfica sobre mecanismos sociales de acceso y uso a Ei.

involucrar interacción entre entidades con diferencias etnolingüísticas o de otro tipo, que se puedan ver reflejadas en la conformación de reservorios de información con diversos grados de diferenciación (McDonald 2016). Representa una instancia intermedia en términos de facilidad del acceso y uso de un espacio determinado (Figura 2b).

En tercer y último lugar, se encuentra el 'sistema de acceso recíproco' a los Ei por parte de distintos grupos bajo diversas formas de negociación. Este es el mecanismo de regulación del acceso a determinados espacios más representado en el registro etnográfico poscolonial a nivel global (Stanner 1965; Lee 1972; Myers 1982; Peterson y Long 1986; Kelly 1995, entre otros). En estos casos, existe una forma de tenencia de la tierra por parte de un grupo, que también puede funcionar en escalas sociales de distinta amplitud. El rasgo característico en este patrón usual a nivel etnográfico es que se requiere un permiso para la circulación y utilización de un espacio, el cual suele estructurarse sobre un principio de reciprocidad en el largo plazo. Sin embargo, estas formas de permiso se organizan sobre diversos aspectos sociales (parentesco, intercambio) preexistentes y no pueden ser solicitadas por cualquier grupo o individuo (Myers 1986). Por otra parte, bajo condiciones de estrés a nivel socioecológico, la negociación de permiso de uso puede ser demorada o incluso resuelta en forma negativa. Cabe esperar que ocurran en el caso de Ei espacial- mente acotados y con gradientes de variación ecológica marcados (Figura 2c).

Este acercamiento a la variación de mecanismos sociales que pueden regir el acceso y uso de los Ei no agota el rango de situaciones representadas a nivel etnográfico, y menos aún aquéllas que pueden haber existido en el registro histórico de largo plazo. El objetivo es sintetizar de modo sencillo el continuum de variación posible. No se plantea que estos mecanismos son determinados en forma lineal por las características ecológicas y biogeográficas de un $\mathrm{Ei}$, aunque sí postulamos que hay una incidencia de estos aspectos (ver Nielsen et al. 2010).

Las dos variables ecológicas aquí mencionadas (contraste ecológico y escala espacial de los Ei) se articulan con las condiciones sociodemográficas imperantes a través del tiempo. A continuación, integramos los planteos biogeográficos con el marco de ideas surgidas de la etnografía, con el objetivo de modelar situaciones arqueológicas para el noroeste de Patagonia, más específicamente el norte de la Provincia del Neuquén y el suroeste de Mendoza, en Argentina, y la región del Maule, en Chile (Figura 1). Aunque no es nuestro interés exclusivo, el foco está puesto en una instancia de poblamiento asimilable a la 'ocupación efectiva' (sensu Borrero 1994-1995), que ya ha comenzado a ser discutida a nivel local (Barberena 2013; Romero y Re 2014; Romero y Barberena 2015). 


\section{* Circulación de información y objetos en ei DEL NOROESTE DE PATAGONIA}

\section{Estacionalidad, capacidad de carga y Ei}

La estacionalidad es una variable ecológica clave para la organización humana del uso del espacio. Permite discutir aspectos inherentes a los Ei tales como movilidad, asentamiento, grados de sedentarismo, duración de las ocupaciones, aumentos demográficos y divisiones políticas, entre otros (Russo y Quitmyer 2008; Reitz et al. 2012). En la región del noroeste de Patagonia donde se enfoca este trabajo se puede considerar la existencia de distintos tipos de Ei. Previamente, se ha discutido el caso de espacios considerados marginales, y potencialmente internodales, sobre la base de su baja capacidad de carga de herbívoros (Barberena 2013). Esto incluye amplios sectores del Monte en el este de Neuquén (Departamento Pehuenches). Aquí utilizamos el marco de los estudios internodales para guiar el análisis arqueológico de contextos diferentes, donde la variable clave es la estacionalidad establecida en función de la altitud y la cobertura de nieve (Paruelo et al. 1998; ver también Pallo 2012). Esta situación es característica de numerosos ambientes de altura a lo largo de los Andes, por lo cual consideramos que el marco conceptual propuesto resulta útil más allá del caso de estudio.

Presentamos una reconstrucción de los patrones de estacionalidad mediante Sistemas de Información Geográfica (Wheatley y Gillings 2002; Conolly y Lake 2009; Lucero 2015) a partir de la cobertura nívea promediada. Se obtuvieron diversas imágenes utilizando el índice de diferencia de nieve normalizado (NDSI) de las fuentes MODIS y Landsat ${ }^{6}$ (Shea et al. 2013) (Figura 3). La información de los análisis espaciales fue promediada y el ráster resultante permitió segmentar el paisaje en tres cortes altitudinales (Tabla 1).

Uno de los rasgos fundamentales en esta región es la fuerte variación topográfica (Figura 3). La presencia de espacios ubicados por sobre los $2000 \mathrm{msnm}$ en la cordillera del Viento y el campo volcánico Tromen extienden

6 Se utilizó la fuente MODIS/Terra Snow Cover Daily L3 Global $500 m$ Grid, Version 5. Comparamos la información de la cobertura de nieve de los inviernos de 2000, 2005, 2010 y 2015 . También realizamos análisis NDSI de imágenes Landsat 7 y 8 de los inviernos de 2002, 2010 y 2015. estas condiciones topográficas hacia el este del cuerpo principal de la cordillera de los Andes. Los espacios señalados en color rojo ( $>2000 \mathrm{msnm}$ ) solo podrían ser ocupados 4 o 5 meses al año, lo cual implica que el resto del tiempo, el paisaje del noroeste de Patagonia presenta una elevada fragmentación. En este marco, se reconocen espacios que permiten una ocupación anual, como los segmentos de baja altitud ( $<1500 \mathrm{msnm}$ ) de los ríos Neuquén, Curi Leuvú y Grande, el río Colorado y la Payunia, en Argentina, y las tierras bajas de la región del Maule, en Chile. Por otra parte, los "Espacios intermedios" (1500-2000 msnm), visualizados en color naranja en la Figura 3, funcionarían como zonas ecotonales de acceso restringido y costo energético elevado en invierno. Estos espacios coinciden con parte de las cuencas de los ríos Neuquén, Barrancas y Grande, algunos sectores de la meseta volcánica de La Payunia (Argentina) y los ríos Guaiquivilo-Melado (Chile).

Determinados sectores de los espacios estacionales por sobre los $1500 \mathrm{msnm}$ presentan un valor clave en diferentes niveles: circulación trasandina, pasturas con elevada productividad estival y acceso a afloramientos primarios de obsidiana de laguna del Maule, con sus afloramientos que se extienden entre Chile y los extremos SO de Mendoza y NO de Neuquén (Seelenfreund et al. 1996; Durán et al. 2004). Estos factores de atracción, sumados al carácter espacialmente circunscripto $y$, particularmente, a su asociación a espacios ubicados a ambos lados de los Andes que habrían funcionado como nodos de asentamiento en forma anual, nos permiten sugerir la siguiente hipótesis de trabajo:

Los segmentos favorables de los Espacios altos de los Andes funcionaron como espacios internodales en el Holoceno Tardio.

Planteamos que, en condiciones demográficas de ocupación efectiva del espacio (Borrero 1994-1995), estos factores pueden conducir al establecimiento de mecanismos sociales que estructuren el acceso y asentamiento humano en los segmentos favorables de los Espacios Altos. Entendemos por espacios favorables aquéllos que, a pesar de la altitud, tienen valores de pendientes $\angle 10^{\circ}$. Desde un punto de vista biogeográfico, este escenario reúne algunas de las propiedades asociadas a las situaciones ' $b$ ' $y$ ' $c$ ' en el modelo de base etnográfica, sugiriendo el probable funcionamiento de sistemas de 'recursos de uso comunal' o sistemas de 'tenencia y acceso recíproco'. El desafío 


\begin{tabular}{|c|c|}
\hline $\begin{array}{l}\text { "Espacios Altos" } \\
\text { (>2000 msnm) }\end{array}$ & $\begin{array}{l}\text { - Espacios con cobertura nívea total durante el invierno. } \\
\text { - Mayor variación estacional. } \\
\text { - Nula accesibilidad y disponibilidad invernal. }\end{array}$ \\
\hline $\begin{array}{l}\text { "Espacios Intermedios" } \\
(1500-2000 \mathrm{msnm})\end{array}$ & $\begin{array}{l}\text { - Espacios con cobertura nívea media durante el invierno. } \\
\text { - Intermedia variación estacional. } \\
\text { - Baja accesibilidad y disponibilidad. }\end{array}$ \\
\hline $\begin{array}{l}\text { "Espacios Bajos" } \\
\text { (<1500 msnm) }\end{array}$ & $\begin{array}{l}\text { - Espacios sin cobertura nívea durante el invierno. } \\
\text { - Baja variación estacional. } \\
\text { - Disponibles en forma anual. }\end{array}$ \\
\hline
\end{tabular}

Tabla 1. Segmentación espacial del área de estudio en función de la topografía y la cobertura de nieve.

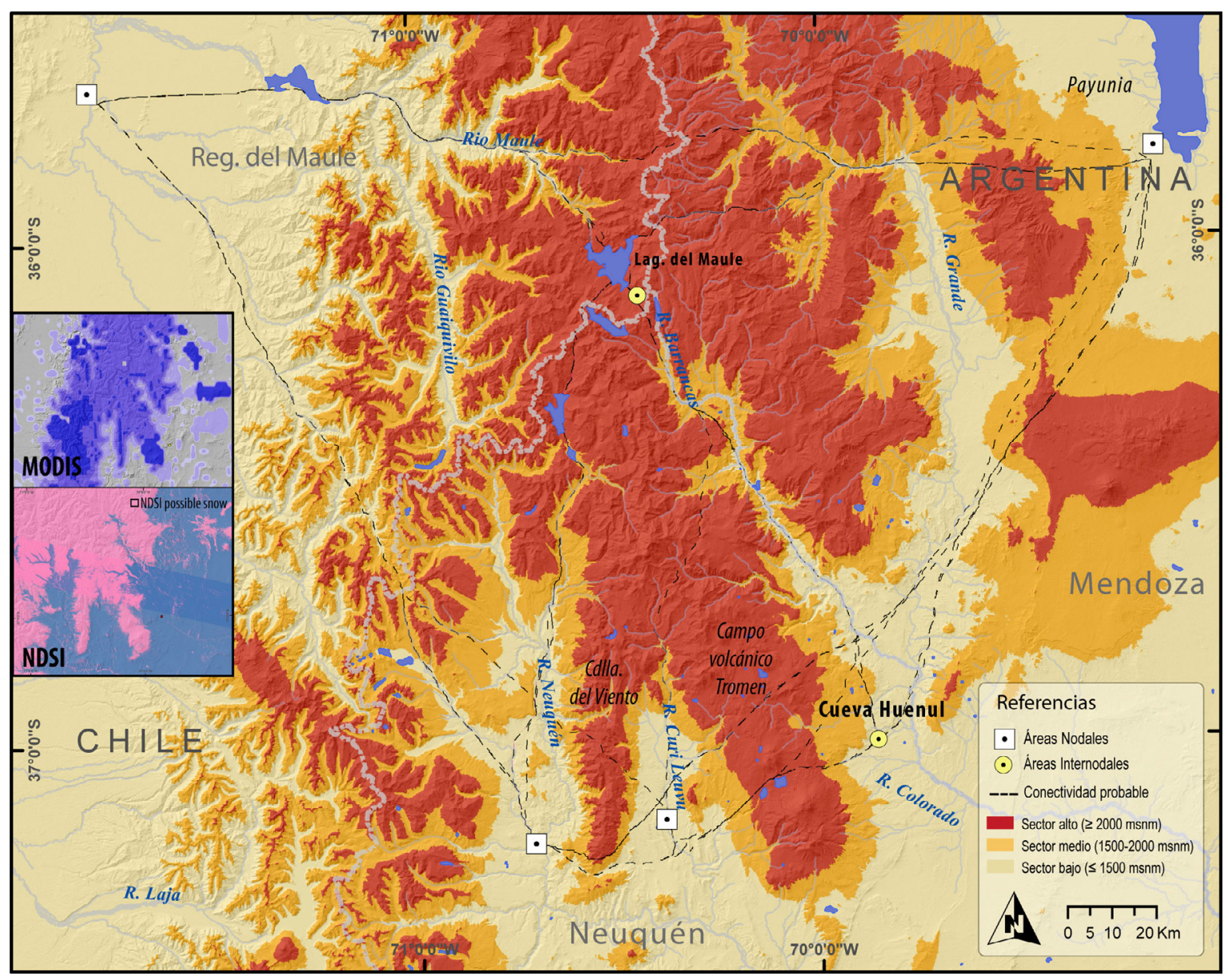

Figura 3. Reconstrucción de estacionalidad y probables áreas nodales e internodales en el Holoceno Tardío.

actual, de carácter teórico y metodológico, es hacer operativa esta propuesta de base biogeográfica y etnográfica en un nivel arqueológico, coherente con el registro de baja resolución temporal característico de Patagonia.

En los apartados siguientes comenzamos a delinear el marco de debate, que integra dos líneas claves de trabajo: el estudio distribucional de representaciones rupestres, tomadas como indicador de las dinámicas de circulación de información y jerarquización del espacio, y la distribución espacial de artefactos de obsidiana cuya procedencia geográfica puede ser determinada a nivel geoquímico, como indicador de los patrones de circulación humana y vectores geográficos en el acceso a las fuentes (Cortegoso et al. 2016). 


\section{Arte rupestre, circulación de información y jerarquización del espacio}

Partimos del supuesto de que las representaciones rupestres son un componente más del registro arqueológico, considerando cada motivo como un artefacto (Aschero 1988). También sostenemos que constituyen una forma de comunicación a partir de la transmisión de información, tal como se ha sugerido desde diversos marcos teóricos (Barton et al. 1994; David y Lourandos 1998; Carden 2008; Re 2010; McDonald y Veth 2011; Scheinsohn 2011; Gallardo et al. 2012, entre otros). En este sentido, entendemos que poseen un valor adaptativo para los grupos humanos (sensu Wobst 1977), por lo cual deben necesariamente ser evaluadas en el contexto de sus condiciones socioecológicas particulares. Así, en tanto demarcación intencional del paisaje introducida por los grupos humanos, el arte rupestre habría desempeñado un rol activo en la construcción del nicho de las poblaciones cazadoras-recolectoras de Patagonia septentrional (Belardi et al. 2016).

Sobre esta base, y en el marco biogeográfico presentado, entendemos que el estudio de la variabilidad espacial y temporal de los motivos rupestres constituye una vía de análisis relevante para evaluar, a partir de la circulación de información, el rol desempeñado por los espacios andinos de altura en la dinámica de interacción intergrupal en Patagonia septentrional durante el Holoceno Tardío (Romero y Re 2014; Romero y Barberena 2015). En este caso, esperamos observar patrones diferenciales en relación con la densidad y diversidad de los motivos rupestres registrados. Esperamos registrar una mayor diversidad de motivos en los Espacios Altos - estacionales- de los Andes, sin que esto se vincule necesariamente a una mayor densidad ya que, a pesar de poseer un valor clave en términos de conectividad y circulación, estos espacios serían ocupados en forma menos intensa a lo largo del año. Este planteo registra un antecedente clave en la propuesta de Belardi y Goñi (2006) y Re (2010) para el caso de las mesetas altas y de uso estacional de la Provincia de Santa Cruz, quienes afirman que dichos espacios, caracterizados por una elevada densidad y diversidad de motivos rupestres, funcionaron como áreas de convergencia poblacional, conectando grupos de procedencias geográficas diversas.

\section{Resultados preliminares}

En trabajos previos hemos comenzado a evaluar estas problemáticas a partir de una primera comparación de las representaciones rupestres documentadas en el noroeste de Patagonia (Romero y Re 2014; Belardi et al. 2016). A nivel global, existe una persistente dificultad metodológica para asignar valor cronológico al arte rupestre, prefiriéndose la aplicación de múltiples indicadores en forma integrada (Aubert 2012). En nuestra región de estudio, hemos tenido la posibilidad de fechar en forma directa mediante radiocarbono una pelvis de guanaco (Lama guanicoe) dibujada con motivos geométricos que son frecuentes en el arte rupestre regional. Esta edad y su contexto, que son caracterizados en detalle en otro trabajo (Romero V. y Barberena 2016), sitúan temporalmente estos diseños en los últimos 2 mil años. Asimismo, aunque no se restringen al Holoceno Tardío, las tasas de descarte de pigmentos en la estratigrafía de Cueva Huenul 1 se disparan en los niveles datados en torno a esta edad (Romero y Barberena 2015). De esta manera, con fines comparativos en una escala más amplia para la cual se carece de fechas absolutas, asumimos una cronología del Holoceno Tardío para la mayoría de las representaciones rupestres, según lo propuesto por otros autores (Gradin 1997-1998; Fernández 2000[1979]; Romero y Re 2014).

En los datos presentados en la Tabla 2, así como en la Figura 4, se observan tanto similitudes como diferencias en relación al arte rupestre documentado en los diversos contextos biogeográficos identificados para el noroeste de Patagonia. Entre las primeras resaltan el predominio de los motivos grabados, 7 así como de los motivos abstractos por sobre los figurativos -si bien en proporciones variables-, y la presencia de un amplio rango de tipos de motivos compartidos, entre los que se destacan distintos tipos de líneas paralelas, figuras de simetría axial, triángulos y rombos adosados y cruciformes. Sostenemos que las semejanzas observadas indican que, al menos

\footnotetext{
7 Se encuentran en curso diversos análisis orientados a evaluar si este patrón refleja elecciones culturales, o si es un resultado actual de la preservación diferencial de los motivos pintados en algunas áreas (Romero Villanueva, en preparación). En este sentido, también se está analizando la oferta regional de recursos necesarios para la ejecución de las imágenes con el fin de estimar su incidencia en la configuración de los patrones tecnológicos observados (p.e. disponibilidad de soportes/pigmentos).
} 


\begin{tabular}{|c|c|c|c|c|c|c|c|}
\hline $\begin{array}{c}\text { Área de } \\
\text { investigación }\end{array}$ & $\begin{array}{c}\mathbf{N} \\
\text { Sitios }\end{array}$ & $\begin{array}{c}\text { Segmento } \\
\text { altitudinal } \\
(\mathrm{msnm})\end{array}$ & $\begin{array}{c}\mathrm{N} \\
\text { motivos }\end{array}$ & Técnicas & $\begin{array}{l}\text { Categorías } \\
\text { de motivos }\end{array}$ & $\begin{array}{c}\text { Indicadores } \\
\text { temporales } \\
\text { relativos }\end{array}$ & $\begin{array}{c}\text { Bibliografía } \\
\text { orientativa }\end{array}$ \\
\hline $\begin{array}{c}\text { Ríos Melado- } \\
\text { Guaiquivilo } \\
\text { y Maule } \\
\text { (Reg. Maule, Chile) }\end{array}$ & 16 & $\begin{array}{l}\text { Alto } \\
\text { (mayoría } \\
2100 \\
\text { a 2600) }\end{array}$ & $\begin{array}{c}+4000 \\
\text { (datos } \\
2 \text { sitios) }\end{array}$ & Grabado & $\begin{array}{c}\operatorname{ABS}(54,07 \%) \\
\operatorname{ANT}(35 \%) \\
\text { ZOO }(9,5 \%) \\
-1 \text { sitio- }\end{array}$ & $\begin{array}{l}\text { Superposiciones } \\
\text { ydiferencias } \\
\text { de pátina }\end{array}$ & $\begin{array}{l}\text { Niemeyer y Weisner } \\
\text { 1972-1973; } \\
\text { Vergara Duplaquet } \\
\text { 1972-1973 }\end{array}$ \\
\hline $\begin{array}{c}\text { Río Neuquén } \\
\text { (NO Pcia. Neuquén, } \\
\text { Arg.) }\end{array}$ & 32 & $\begin{array}{l}\text { Alto a } \\
\text { Intermedio } \\
\text { (mayoría } \\
\text { ca. 2000) }\end{array}$ & $\begin{array}{l}+2800 \\
(1 \text { sitio })\end{array}$ & $\begin{array}{c}\text { mayoría } \\
\text { Grabado } \\
\text { (escasa } \\
\text { Pintura) }\end{array}$ & $\begin{array}{l}\text { ABS }(95 \%) \\
\text { FIG }(5 \% \\
\text { ANT y ZOO) } \\
-1 \text { sitio- }\end{array}$ & $\begin{array}{l}\text { Superposiciones } \\
\text { ydiferencias } \\
\text { de pátina }\end{array}$ & $\begin{array}{l}\text { Fernández } 2000 \\
\text { [1979]; Vega 2016; } \\
\text { Vega et al. } 2016\end{array}$ \\
\hline $\begin{array}{l}\text { Río Curi Leuvú } \\
\text { (NO Pcia. Neuquén, } \\
\text { Arg.) }\end{array}$ & 11 & $\begin{array}{c}\text { Bajo a } \\
\text { Intermedio }\end{array}$ & $\begin{array}{l}+300 \\
(1 \text { sitio })\end{array}$ & $\begin{array}{l}\text { Pinturay } \\
\text { Grabado }\end{array}$ & $\begin{array}{c}\text { predominio ABS } \\
\text { escasos ANT, ZOO } \\
\text { ABS ( } 87 \%) \\
\text { FIG }(13 \%, \\
\text { ANT y ZOO) } \\
\text {-1 sitio- }\end{array}$ & SD & $\begin{array}{c}\text { Fernández 1978; } \\
\text { Hajduk y Cúneo 2009; } \\
\text { Vargas } 2015\end{array}$ \\
\hline $\begin{array}{c}\text { Río Barrancas } \\
\text { (NE Pcia. Neuquén, } \\
\text { Arg.) }\end{array}$ & 9 & $\begin{array}{c}\text { Bajo a } \\
\text { Intermedio } \\
\text { (mayoría } \\
1000 \text { a 1500) }\end{array}$ & $\begin{array}{c}414 \\
\text { (total) }\end{array}$ & Pintura & $\begin{array}{l}\operatorname{ABS}(65,43 \%) \\
\operatorname{ANT}(3,29 \%) \\
\operatorname{ZOO}(2,88 \%)\end{array}$ & $\begin{array}{l}\text { Superposiciones } \\
\begin{array}{c}\text { (N: } 26) \text {; desvaído } \\
\text { diferencial } \\
\text { de pinturas; fecha } \\
\text { diseño similar en } \\
\text { soporte móvil }\end{array}\end{array}$ & $\begin{array}{l}\text { Romero y Re 2014; } \\
\text { Romero 2016; Romero } \\
\text { V. y Barberena } 2016\end{array}$ \\
\hline $\begin{array}{c}\text { Payunia } \\
\text { (SO Pcia. Mendoza, } \\
\text { Arg.) }\end{array}$ & 16 & $\begin{array}{c}\text { Bajo } \\
\text { (mayoría } \\
\text { ca. 1000) }\end{array}$ & SD & $\begin{array}{l}\text { Pinturay } \\
\text { Grabado }\end{array}$ & $\begin{array}{l}\text { predominio ABS } \\
\text { escasos ANT, ZOO }\end{array}$ & $\mathrm{SD}$ & $\begin{array}{l}\text { Schobinger 1978, } \\
\text { 2002; Schobinger y } \\
\text { Gradin 1985; } \\
\text { Gil } 2006\end{array}$ \\
\hline
\end{tabular}

Referencias: $\mathrm{NO}=$ noroeste, $\mathrm{NE}=$ noreste, $\mathrm{SO}=$ Sudoeste, Reg.= Región, Pcia.= Provincia, Arg.= Argentina, $\mathrm{SD}=\mathrm{Sin}$ datos, $\mathrm{ABS}=\mathrm{Abstractos}$, FIG $=$ Figurativos, $\mathrm{ANT}=$ Antropomorfos y $\mathrm{ZOO}=$ Zoomorfos.

Tabla 2. Áreas con representaciones rupestres consideradas en escala macrorregional.

durante el Holoceno Tardío, tuvo lugar una dinámica de circulación de información compartida entre espacios geográfica y ecológicamente diversos de esta macrorregión, que habría permitido su articulación dentro de las redes de circulación y asentamiento de las poblaciones que habitaron la zona (Romero y Re 2014). Esta sugerencia es coincidente con lo planteado por otros autores para este momento, a partir de la amplia distribución espacial de diseños similares plasmados sobre diversos tipos de materiales y soportes (p.e. arte rupestre, placas líticas, hachas grabadas, cáscaras de huevo de Rheidae, tiestos cerámicos, etc.) (citas en Romero y Barberena 2015).

Por otra parte, las diferencias observadas entre las distintas áreas en términos de la densidad de motivos, los porcentajes variables de las categorías presentes y la presencia-ausencia de determinadas categorías y tipos de motivos, dan cuenta de una circulación diferencial de información al interior de la macrorregión. En particular, se observa que las áreas ubicadas a mayor altitud y cuyo uso es estacional se destacan por presentar las mayores cantidades de motivos (Tabla 2 y Figura 4). Asimismo, en una de ellas -río Guaiquivilo-, Niemeyer y Weisner (1972-1973) definieron tempranamente el 'estilo Guaiquivilo' que, según desarrollos posteriores de otros autores, se caracterizaría por combinar elementos presentes en los 'estilos' de pisadas, paralelas y grecas (sensu Menghin 1957). Sobre la base de estas observaciones, preliminarmente sugerimos que esta zona concentraría la mayor diversidad de tipos de motivos documentados, incluyendo algunos que son característicos de otras regiones de Patagonia pero se encontrarían ausentes en las demás áreas de la macroescala considerada (Belardi et al. 2016; Romero 2016).

De esta manera, la mayor frecuencia de motivos en conjunto con la mayor diversidad de tipos y diseños avalan la hipótesis antes referida y sugieren una jerarquización mayor de los Ei estacionales respecto de otros contextos biogeográficos, en cuanto a la circulación de información 


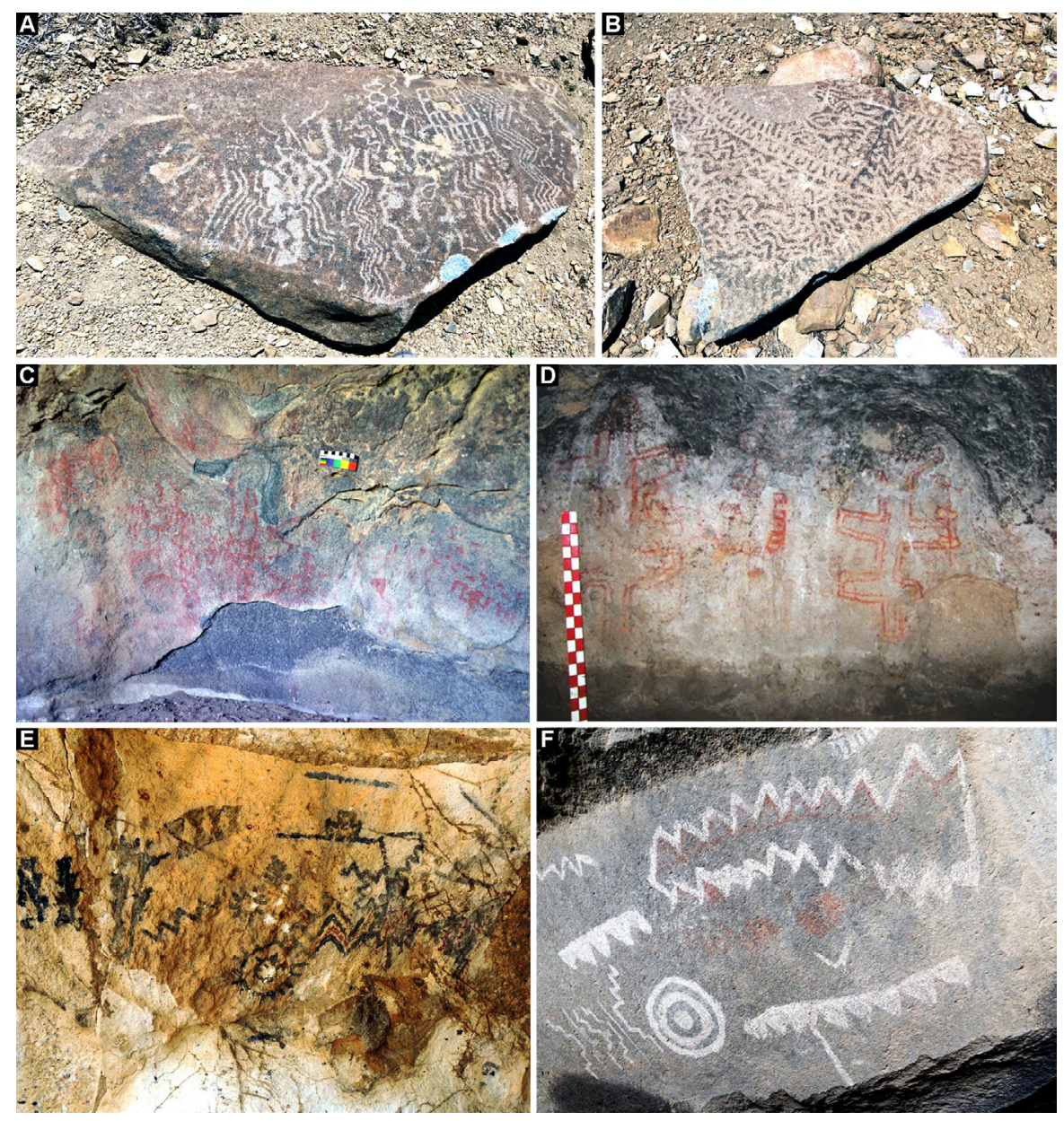

Referencias: A y B) Bloques grabados del sitio Colo Michi Có (río Neuquén, Provincia del Neuquén, Argentina); C y D) Foto original de pinturas rupestres de los sitios El Ciénego 3 y Cueva Huenul I (río Barrancas, Provincia del Neuquén, Argentina); E y F) Foto original de pinturas rupestres de los sitios Las Tinajas y Gruta del Indio (Payunia, Provincia de Mendoza, Argentina). A, B, E y F: sin escala en el original. Créditos: A a D: los autores. E y F: gentileza Laura Hart.

Figura 4. Ejemplos del arte rupestre en las áreas comparadas.

para los grupos humanos durante el Holoceno Tardío. Asimismo, el análisis de las representaciones rupestres evidencia una diacronía - a partir de la presencia de superposiciones y diferentes grados de pátina entre los grabados- en la ejecución de los motivos registrados en estos espacios, que permite sostener su ocupación de manera redundante durante dicho lapso. Creemos que estas observaciones dan cuenta de la influencia ejercida por los aspectos estratégicos antes referidos de los Ei estacionales para su uso por parte de las poblaciones humanas y que se relacionan, fundamentalmente, con su rol de vías de tránsito estacional que permiten la circulación trasandina y la conectividad (sensu Fitzhugh et al. 2011) de amplios espacios con usos potencialmente diversos (p.e. áreas nodales de ocupación anual, acceso a afloramientos primarios de obsidiana, ámbitos con buena disponibilidad estacional de recursos silvestres: iterritorios de caza?). Así, de modo similar a lo observado por Belardi y Goñi (2006) y Re (2010) para la Provincia de Santa Cruz, los espacios estacionales del noroeste de Patagonia también pueden ser conceptualizados como espacios de 'convergencia poblacional' propicios para la circulación de información, en tanto serían lugares de potencial uso compartido, aunque no necesariamente en forma simultánea. 
En forma exploratoria, sugerimos que las representaciones rupestres de los Ei estacionales pueden ser indicadores de tipos particulares de movilidad humana, definidos por Whallon (2006) como 'de redes' e 'informacional', los cuales habrían sido implementados en forma simultánea con los de tipo residencial y logístico durante el Holoceno Tardío, en coincidencia con un probable contexto demográfico donde gran parte de los espacios disponibles se encuentra integrada a los territorios humanos (Eerkens 1999). Las formas de movilidad de redes e informacional tienen por objeto que los grupos se muevan por un territorio o se agreguen en determinados lugares para intercambiar nueva información o actualizar su conocimientos sobre ese territorio y sus recursos, así como sobre los demás grupos que puedan encontrarse al transitarlo (Whallon 2011). Asimismo, al favorecer la circulación de información sobre distintos ambientes y la generación de derechos y obligaciones entre diferentes grupos, sientan las bases para el desarrollo de 'redes de seguridad' de valor adaptativo en ambientes inciertos como el del noroeste de Patagonia, dada su elevada fragmentación.

\section{Geoquímica de obsidianas: procedencia y trayectorias de reducción lítica}

La caracterización química de obsidianas es una herramienta metodológica ampliamente establecida para estudiar la procedencia geológica y, sobre esta base, la procedencia geográfica de artefactos (p.e. Jones et al. 2003; Shackley 2005). En el marco de nuestros objetivos, los estudios de obsidianas cumplen las siguientes funciones: en el nivel más general, informan sobre patrones espaciales de movilidad y transporte (mecanismos directos) e intercambio (mecanismos indirectos) de artefactos. En un nivel más específico, cuando un tipo químico tiene una procedencia conocida en el espacio, las distribuciones en el espacio pueden reflejar vectores geográficos dominantes en la circulación humana. Recientemente se ha presentado un primer caso de análisis en este sentido para los Andes de Mendoza y Neuquén (Cortegoso et al. 2016). Por último, la evaluación de la estructura espacial de las fuentes de obsidiana desarrollada mediante estudios geoarqueológicos y geoquímicos (Fernández et al. 2016) se complementa con estudios tecnológicos, a fin de establecer trayectorias de reducción de instrumentos líticos en el espacio.
El noroeste de Patagonia es una región ideal para el desarrollo de esta línea, dada la amplia disponibilidad de fuentes de obsidiana con perfiles geoquímicos particulares (Stern 2004). Como cabe esperar, las obsidianas se encuentran ampliamente representadas en los conjuntos líticos de la macrorregión. El programa de caracterización geoquímica de fuentes y artefactos iniciado en 2004 (Durán et al. 2004; Giesso et al. 2011; Cortegoso et al. 2012; Fernández et al. 2016) ofrece una sólida base para nuestro trabajo actual. El potencial de complementariedad entre los patrones espaciales en el transporte y descarte de artefactos de obsidiana -rastreado desde un punto de vista geoquímico y tecnológico- y el registro de representaciones rupestres es enorme. Un enfoque anclado en la dinámica de nodos e internodos resulta clave para realizar este potencial.

En la Figura 5 se presenta la localización de las principales fuentes de obsidiana en la región, incluyendo las fuentes de Laguna del Maule (primaria y secundaria) y Cerro Huenul (secundaria). Los dos tipos químicos reconocidos para laguna del Maule se encuentran disponibles principalmente en los espacios favorables estacionales que aquí caracterizamos como potenciales internodos. Sin embargo, estudios geoarqueológicos actualmente en marcha sugieren que esta obsidiana ha experimentado procesos secundarios de redistribución asociados a la dinámica fluvial del río Barrancas hacia el sureste y, probablemente, el río Neuquén hacia el sur (Fernández et al. 2016, fig. 6). En este sentido, a diferencia de lo considerado en trabajos previos, esta obsidiana no sería un marcador fehaciente de acceso a los Espacios Altos de los Andes, ya que pudo haber sido obtenida a lo largo de la cuenca del Barrancas y, probablemente, el río Colorado. Este conocimiento geoarqueológico reciente relativiza el carácter de la obsidiana del Maule como indicador de acceso humano (directo o indirecto) a los mismos.

Hasta el momento se ha caracterizado un total de 303 artefactos procedentes de contextos de superficie y estratigrafía en nuestra región de trabajo (Fernández et al. 2016). Una parte de estos conjuntos, procedentes de los sitios Cueva Huenul 1 y Cueva Huenul 3 (Barberena 2015; Fernández et al. 2016), proviene de contextos de estratigrafía con fechas asociadas, que los sitúan mayormente en los últimos 1500 años. Esta muestra será ampliada en el corto plazo mediante la caracterización 
geoquímica de la secuencia del sitio Cueva Yagui, con una edad de base de ca. 8000 años AP (Romero Villanueva et al. en preparación). Cabe destacar que estos sitios son los que presentan las mayores frecuencias de representaciones rupestres y pigmentos en estratigrafía, con lo cual ofrecen un marco adecuado para situar ambas evidencias a nivel temporal.

En paralelo, actualmente se encuentra en desarrollo una incipiente línea de análisis de hidratación de obsidianas procedentes de superficie y estratigrafía. Aunque en la presente instancia no se espera obtener edades con precisión cuantitativa, esto permitirá evaluar la diacronía y el tempo de formación de conjuntos de superficie.

En la Figura 6 se presentan las determinaciones geoquímicas de artefactos procedentes de la región de estudio, donde se diferencian las fuentes Cerro Huenul y Laguna del Maule, con sus subtipos químicos 1 y 2 (Seelenfreund et al. 1996). A nivel espacial, este muestreo no es homogéneo y no incluye aún muestras procedentes de los potenciales Ei de Espacios Altos, cuyo muestreo de campo está en proceso. Estas muestras proceden de espacios ubicados entre 900 y $1700 \mathrm{msnm}$ (aprox.) entre la localidad Huenul y el campo volcánico Tromen, que ha sido nuestro foco principal de trabajo de campo hasta el momento (Barberena 2013).

Los datos disponibles marcan el predominio de obsidiana Cerro Huenul (90\%) en relación con los dos subtipos de Laguna del Maule (10\%). Esta baja pero importante frecuencia de artefactos procedentes del Maule podría ser interpretada como indicador de acceso recurrente a los Espacios Altos (Ei?) desde las localidades aquí muestreadas, ubicadas entre $60-80 \mathrm{~km}$ del ámbito de la fuente primaria. Sin embargo, los recientes hallazgos geoarqueológicos mencionados relativizan el sustento de esta interpretación espacial, sugiriendo el posible acceso directo a esta obsidiana desde Espacios Intermedios y Bajos a lo largo de la cuenca del río Barrancas y, eventualmente, el río Colorado. Más allá de esto, el estudio tecnológico de esta muestra indica trayectorias espaciales diferentes para los subconjuntos procedentes de Cerro Huenul y Laguna del Maule. Mientras que la muestra de Cerro Huenul, que es de disponibilidad inmediata ( $\$ 5 \mathrm{~km}$, sensu Civalero y Franco 2003), se encuentra representada por todas las instancias en el proceso de reducción, incluyendo lascas primarias, núcleos, desechos e instrumentos, los artefactos asignados a Laguna del Maule tan solo reflejan instancias avanzadas de dicho proceso de reducción representadas por lascas internas e instrumentos, mayormente puntas de proyectil (Fernández et al. 2016). Aunque no se puede descartar una incidencia de los diferentes tamaños de cada subconjunto, creemos que el patrón registrado es consistente con la información sobre la estructura de la fuente Laguna del Maule que, aun estando disponible en la cuenca del río Barrancas (Figura 5), se encuentra a una distancia mínima de $10 \mathrm{~km}$ con respecto a los conjuntos arqueológicos muestreados.

En referencia al marco de los estudios internodales, la información actual sobre la estructura de las fuentes de obsidiana nos permite identificar los objetivos que deben cumplirse en el corto plazo, así como comprender los límites que enfrentamos en términos de resolución espacial. Dado que los tipos químicos de obsidiana referidos no están disponibles en localizaciones discretas, sino que tienen múltiples focos de disponibilidad, no podemos proceder a un análisis lineal de distancias de transporte. Para cada localidad, debemos ajustar la distancia mínima a cada fuente y posicionar los conjuntos caracterizados geoquímicamente en términos de instancias de reducción representadas (Jones et al. 2003; Clarkson 2008). La actividad clave a futuro es caracterizar a nivel geoquímico y tecnológico conjuntos procedentes de los espacios estacionales de altura. Esto permitirá integrar este indicador sobre una base sólida al debate sobre Ei, al cual las representaciones rupestres contribuyen actualmente.

\section{* Reflexiones finales y PERSPECTIVAS FUtURAS}

En este trabajo buscamos realizar un aporte inicial a los estudios de Ei a partir de la evaluación del rol desempeñado por espacios estacionales de altura en la dinámica de interacción social intergrupal en el noroeste de Patagonia. En este esquema la biogeografía desempeña un rol clave para la caracterización de los espacios que pudieron haber funcionado como internodos en determinados momentos históricos, en un contexto donde la estacionalidad es una variable clave que fragmenta el paisaje durante gran parte del año. Las dos líneas de evidencia postuladas - motivos rupestres y geoquímica de obsidianas- permiten distinto grado de avance en referencia al estudio de Ei. Las representaciones rupestres marcan una 


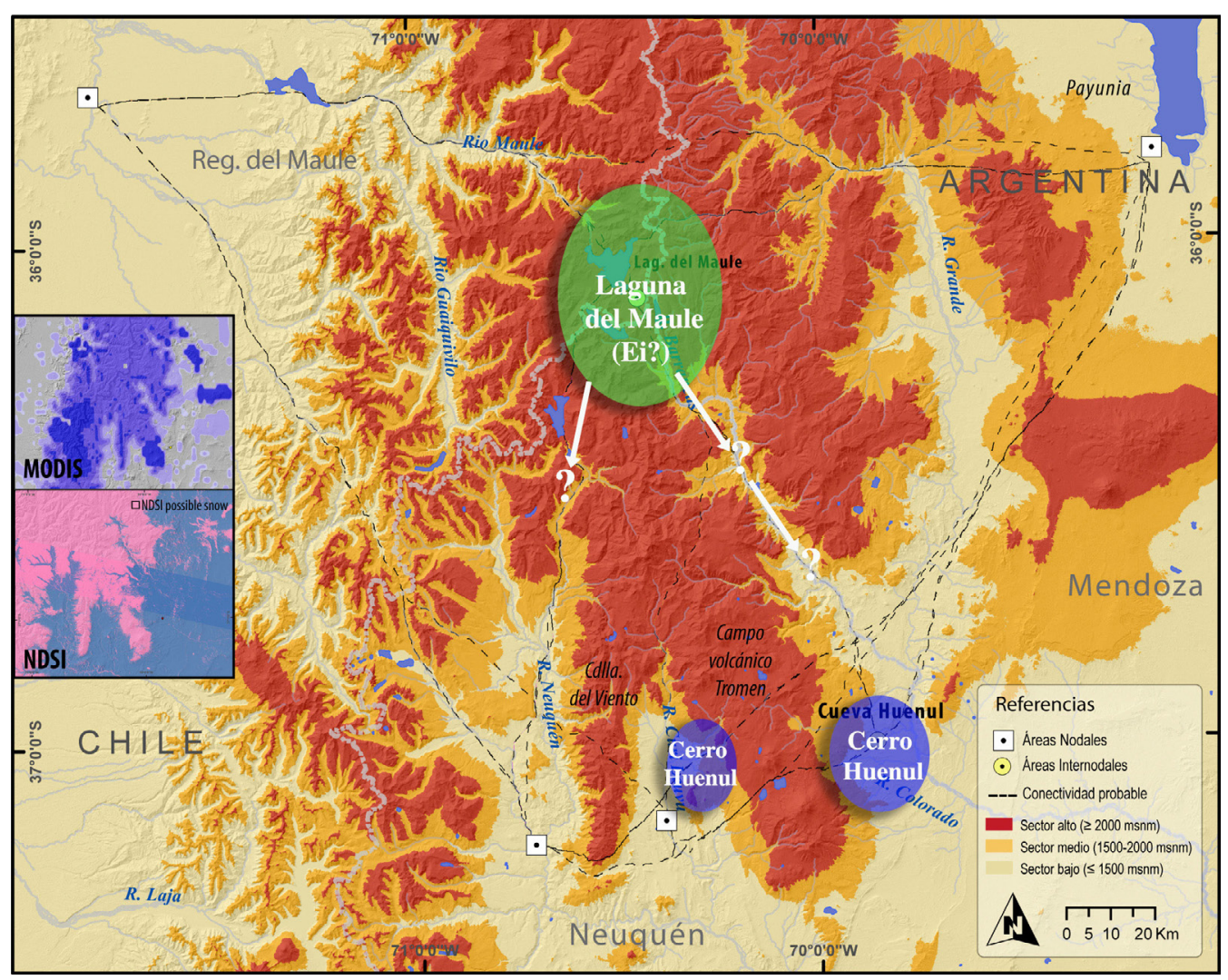

Figura 5. Localización de las principales fuentes de obsidiana en la región de estudio.

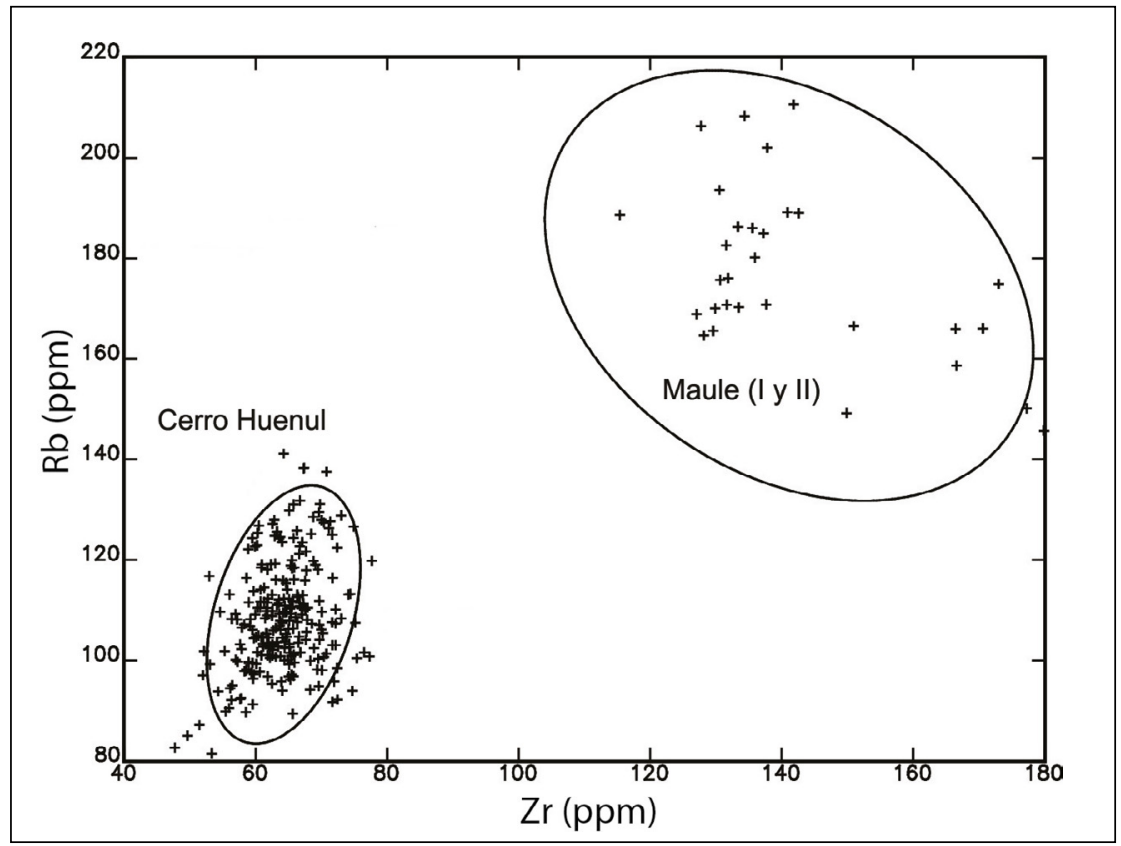

Figura 6. Caracterización química de artefactos en el norte de Neuquén ( $\mathrm{N}=303)$. 
vía de caracterización de las dinámicas de circulación de información implementadas en estos espacios, así como destacan las jerarquías que ocuparon en las redes de circulación y asentamiento de las poblaciones que habitaron la región. Los datos geoquímicos nos han permitido establecer un punto de partida para situar los estudios de obsidianas en este marco de trabajo. Creemos que la evaluación de la existencia (o no) de vectores dominantes de circulación humana y acceso a los Espacios Altos ocupará un lugar importante en este debate. Esto deberá ser evaluado a nivel geoquímico y tecnológico.

De este trabajo preliminar surge con claridad una agenda interdisciplinaria de trabajo para los próximos años. En referencia al arte rupestre, debemos afinar el grano de la comparación de los tipos de motivos, sus diseños y frecuencias (Romero Villanueva 2016, 2016 en preparación). Esto nos permitirá ahondar en los patrones observados en distintos Ei, que pueden ser relevantes para evaluar los mecanismos sociales de acceso. Estamos realizando avances concretos para ajustar la cronología del arte rupestre, tanto a partir del fechado de diseños ejecutados sobre soportes móviles como de la datación directa de pinturas rupestres que contienen carbón, lo cual ha sido recientemente confirmado mediante espectroscopía Raman (Marcela Sepúlveda, com. pers.). En relación al estudio de obsidianas, tenemos que profundizar la caracterización geoarqueológica y geoquímica de las fuentes como un paso necesario para una reconstrucción robusta de los circuitos de movilidad humana. Asimismo, avanzaremos en producir información temporal relativa mediante estudios de hidratación de obsidianas. La capacidad de posicionar las evidencias tratadas en el tiempo es claramente uno de los desafíos futuros.

Desde el punto de vista teórico, nos interesa enfatizar que el objetivo de nuestra propuesta no radica en identificar mecanismos específicos a nivel arqueológico (recursos de uso comunal, sistemas de tenencia y acceso recíproco), ya que esto requiere una resolución que probablemente no sea alcanzable. Por el contrario, creemos que se pueden generar expectativas para múltiples líneas de trabajo referidas a la demarcación de paisajes, que sean relevantes para ubicar el uso humano de un Ei en un período determinado en una posición relativa dentro del espectro de variación en la facilidad al acceso a un espacio definido sobre la base de información etnográfica (Figura 2). En este sentido, as- piramos a una menor resolución analítica, aunque con un mayor poder explicativo en el registro de larga duración. En paralelo a estos desarrollos, tenemos planeado incorporar datos provistos por análisis de isótopos de estroncio (87Sr/86Sr) en restos óseos humanos, que permiten evaluar los espacios ocupados por un individuo en distintos momentos de su vida, constituyendo un indicador de su procedencia geográfica (Knudson et al. 2012). Estos estudios serán claves para discutir, en la escala de análisis del individuo, los lugares desde donde se accede a los espacios internodales, así como su uso, circulación y asentamiento. Esta información facilitará ampliar las posibilidades de comparación con regiones vecinas, como la provincia de Mendoza y Chile (Barberena et al. 2016).

Los resultados obtenidos hasta el momento nos invitan a continuar investigando este tipo de espacios, que cumplen un rol estratégico para las sociedades humanas en términos de conectividad en una escala espacial amplia mediante la circulación de información, objetos y personas. Esperamos que la discusión iniciada, que busca otorgar sentido espacial y demográfico a determinados paisajes arqueológicos, resulte fructífera en la identificación de indicadores arqueológicos específicos sobre los diferentes mecanismos sociales de interacción que pudieron haber regulado el acceso, la circulación y el uso de este tipo de espacios. Asimismo, y en un sentido más amplio, con este trabajo buscamos generar un aporte teórico-metodológico a los estudios de Ei que podrá contribuir a un marco comparativo sobre su dinámica social, geográfica y temporal.

Agradecimientos A Gonzalo Pimentel y José Berenguer por la coordinación del simposio y de este volumen. A Axel Nielsen por sus interesantes comentarios al simposio. A los evaluadores anónimos por sus aportes constructivos al trabajo. A Marcela Sepúlveda por su apoyo y guía para el trabajo arqueométrico con pigmentos. Esta investigación es financiada por los proyectos PICT 20140940 y PIP 2015-2017 GI (Argentina). Especialmente a las autoridades de Barrancas y Buta Ranquil (Provincia del Neuquén, Argentina) y a los arqueólogos de la Secretaría de Cultura de dicha provincia (Claudia Della Negra, Estela M. Cúneo y Pablo Azar) por colaborar con el desarrollo de nuestro trabajo. A Laura Hart por facilitar imágenes de arte rupestre. Un agradecimiento afectuoso a los demás miembros del equipo que han colaborado en las tareas de campo y gabinete. 


\section{* Referencias citadas}

AGRAWAL, A. 2003. Sustainable governance of common-pool resources: Context, methods, and politics. Annual Review of Anthropology $32(1): 243-262$.

ASCHERO, C. A. 1988. Pinturas rupestres, actividades y recursos naturales: un encuadre arqueológico. En Arqueología Contemporánea Argentina. Actualidad y Perspectivas, H. Yacobaccio (Ed.), pp. 109-145. Ediciones Búsqueda, Buenos Aires.

AUBERT, M. 2012. A review of rock art dating in the Kimberley, Western Australia. Journal of Archaeological Science 39: 573-577.

BAILEY, G. 2007. Time perspectives, palimpsets and the archaeology of time. Journal of Anthropological Archaeology 26(2): 198-223.

BARBERENA, R. 2008. Arqueología y biogeografía humana en Patagonia meridional. Sociedad Argentina de Antropología, Buenos Aires.

BARBERENA, R. 2013. Biogeografía, competencia y demarcación simbólica del espacio: modelo arqueológico para el norte de Neuquén. Intersecciones en Antropología 14:367-382.

BARBERENA, R. 2015. Cueva Huenul 1 Archaeological Site (Northwestern Patagonia, Argentina): Initial Colonization and midHolocene Demographic Retraction. Latin American Antiquity 26(3):304-318.

BARBERENA, R., A. HAJDUK, A. GIL, G. NEME, V. DURÁN, M. D. GLASCOCK, M. GIESSO, K. BORRAZZO, M. P. POMPEI, M. L. SALGÁN, V. CORTEGOSO, G. VILLAROSA y A. RUGHINI. 2011. Obsidian in the south-central Andes: geological, geochemical, and archaeological assessment of north Patagonian Sources (Argentina). Quaternary International 245: 25-36.

BARBERENA, R., V. DURÁN, P. NOVELLINO, D. WINOCUR, A. BENÍTEZ, A. TESSONE, M. N. QUIROGA, E. MARSH, A. GASCO, V. CORTEGOSO, G. LUCERO, C. LLANO y K. J. KNUDSON. 2016. Scale of human mobility in the southern Andes (Argentina and Chile): a preliminary framework based on strontium and oxygen isotopes. American Journal of Physical Anthropology. En evaluación.

BARTON, C. M., G. A. CLARK y A. E. COHEN. 1994. Art as information: explaining Upper Paleolithic art in Western Europe. World Archaeology 26(2): 185-207.

BAYMAN, J. y A. sullivan iii. 2008. Property, Identity, and Macroeconomy in the Prehispanic Southwest. American Anthropologist $110(1): 6-20$.
BELARDI, J. B. y R. A. GOÑI. 2006. Representaciones rupestres y convergencia poblacional durante momentos tardíos en Santa Cruz (Patagonia argentina). El caso de la meseta del Strobel. En Tramas en la piedra. Producción y usos del arte rupestre, D. Fiore y M. M. Podestá (Eds.), pp. 85-94. World Archaeological Congress, SAA-INAPL, Buenos Aires.

BELARDI, J. B., F. CARBALLO MARINA, T. J. BOURLOT y A. RE. 2009. Paisajes arqueológicos, circulación e interacción en diferentes escalas: una perspectiva desde el lago Tar (Provincia de Santa Cruz). En Arqueología de la Patagonia: una mirada desde el último confín, tomo 1, M. Salemme, F. Santiago, M. Álvarez, E. Piana, M. Vázquez y E. Mansur (Eds.), pp. 219-231. Editorial Utopías, Ushuaia.

BELARDI, J. B., R. BARBERENA, R. GOÑI y A. RE. 2016. The Development of a Legacy: Evolution, Biogeography, and Archaeological Landscapes. En Darwin's Legacy: The Status of Evolutionary Archaeology in Argentina, M. Cardillo y H. Muscio (Eds.), pp. 83-94. South American Archaeology Series 24. Archaeopress, Oxford.

BERENGUER, J. 2010. Estrategias ocupacionales incaicas en dos espacios internodales del norte de Chile. EnActas del XVII Congreso Nacional de Arqueología Chilena Valdivia 2006, tomo 2, L. Adán y D. Munita (Eds.), pp. 1389-1402. Ediciones Kultrún, Valdivia.

BERENGUER, J. y G. PIMENTEL. 2010. Presentación. Simposio Arqueología de los espacios vacíos: Una aproximación internodal a las relaciones intersocietales. En Actas del XVII Congreso Nacional de Arqueología Chilena Valdivia 2006, tomo 2, L. Adán y D. Munita (Eds.), pp. 1305-1308. Ediciones Kultrún, Valdivia.

BINFORD, L. R. 1977. Forty-seven trips: a case study in the character of archaeological formation processes. En Stone Tools as Cultural Markers: Change, Evolution, and Complexity, R. V. S. Wright (Ed.), pp. 24-36. Australian Institute of Aboriginal Studies, Canberra.

BORRero, L. A. 1994-1995. Arqueología de la Patagonia. Palimpsesto 4:9-69.

BORRERO, L. A. 2004. The Archaeozoology of Andean 'Dead Ends' in Patagonia: Living near the Continental Ice Cap. En Colonisation, Migration and Marginal Areas. A Zooarchaeological approach, M. S. Mondini, A. S. Muñoz y S. Wickler (Eds.), pp. 5561. Oxbow Books, Oakville.

BORRERO, L. A. 2005. The Archaeology of the Patagonian Deserts: Hunter-Gatherers in a Cold Desert. En Desert Peoples. Ar- 
chaeological Perspectives, P. Veth, M. Smith y P. Hiscock (Eds.), pp. 142-158. Blackwell, Oxford.

BORRERO, L. A. y R. BARBERENA. 2006. Hunter-gatherer home ranges and marine resources. An archaeological case from southern Patagonia. Current Anthropology 47(5): 855-867.

BORRERO, L. A. y K. BORRAZZO. 2011. La geografía cultural del sudoeste de Patagonia continental. En Bosques, montañas y cazadores. Investigaciones arqueológicas en Patagonia meridional, L. A. Borrero y K. Borrazzo (Eds.), pp. 7-35. CONICET-IMHICIHU, Buenos Aires.

CARDEN, N. 2008. Imágenes a través del tiempo. Arte rupestre y construcción social del paisaje en la Meseta Central de Santa Cruz. Sociedad Argentina de Antropología, Buenos Aires.

CHACAMA, J. 2010. Un tiempo, un espacio, dos identidades. Coles y carangas en la precordillera de Arica, norte de Chile, siglos X-XV. En Actas del XVII Congreso Nacional de Arqueología Chilena Valdivia 2006, tomo 2, L. Adán y D. Munita (Eds.), pp. 1331-1340. Ediciones Kultrún, Valdivia.

CIVALERO, M. T. y N. V. FRANCO. 2003. Early human occupations in Western Santa Cruz Province, Southernmost South America. Quaternary International 109: 77-86.

CLARKSON, C. J. 2008. Lithics and landscape archaeology. En Handbook of Landscape Archaeology, B. David y J. Thomas (Eds.), pp. 490-501. Left Coast Press, Walnut Creek.

CONOLLY, J. y M. LAKE. 2009. Sistemas de Información Geográfica aplicados a la Arqueología. Bellaterra, Barcelona.

CORTEGOSO, V., G. NEME, M. GIESSO, V. DURÁN y A. GIL. 2012. El uso de la obsidiana en el sur de Mendoza. En Paleoecología humana en el Sur de Mendoza, G. Neme, A. Gil (Eds.), pp. 181211. Sociedad Argentina de Antropología, Buenos Aires.

CORTEGOSO, V., R. BARBERENA, V. DURÁN y G. LUCERO. 2016. Geographic vectors of human mobility in the Andes (34$36^{\circ} \mathrm{S}$ ): comparative analysis of 'minor' obsidian sources. Quaternary International 422: 81-92.

DAVID, B. y H. LOURANDOS. 1998. Rock art and socio-demography in northeastern Australian prehistory. World Archaeology 30 (2): 193-219.

DURÁN, V., M. GIESSO, M. D. GLASCOCK, G. NEME, A. GIL y L. SANHUEZA. 2004. Estudio de fuentes de aprovisionamiento y redes de distribución de obsidiana durante el Holoceno Tardío en el sur de Mendoza (Argentina). Estudios Atacameños 28: 25-43.
DYSON-HUDSON, R. y E. A. SMITH. 1978. Human territoriality: an ecological reassessment. American Anthropologist 80: 21-41.

EERKENS, J. W. 1999. Common Pool Resources, Buffer Zones, and Jointly Owned Territories: Hunter-Gatherer Land and Resource Tenure in Fort Irwin, Southeastern California. Human Ecology 27(2): 297-318

FERNÁNDEZ, J. 1978. Corpus de arte prehistórico Neuquino. Primera parte. Revista del Museo Provincial 1(1): 17-93.

FERNÁNDEZ, J. 2000 [1979]. Las piedras con marcas de la cordillera del Viento. Arte rupestre en el departamento Minas, Neuquén, Argentina. Sociedad Argentina de Antropología, Buenos Aires.

FERNÁNDEZ, M. V., BARBERENA, R., M. GIESSO, A. RUGHINI, V. CORTEGOSO, V. DURÁN, G. ROMERO V., K. BORRAZZO, G. LUCERO, R. GARVEY, B. L. MACDONALD y M. D. GLASCOCK. 2016. Obsidian geochemistry, geoarchaeology, and lithic technology in northwestern Patagonia (Argentina). Journal of Archaeological Science: Reports. En evaluación.

FIGUERERO TORRES, M. J. y G. L. MENGONI GOÑALONS. 2006. Lugares persistentes y vacíos ocupacionales en sociedades cazadoras-recolectoras de la Patagonia centro-meridional. En Actas del XVII Congreso Nacional de Arqueología Chilena Valdivia 2006, tomo 2, L. Adán y D. Munita (Eds.), pp. 1319-1330. Ediciones Kultrún, Valdivia.

FITZHUGH, B., S. COLBY PHILLIP y E. GJESFJELD. 2011. Modeling Variability in Hunter-Gatherer Information Networks: An Archaeological Case Study from the Kuril Islands. En Information and its Role in Hunter-Gatherer Bands, R. Whallon, W. Lovis y R. Hitchcock (Eds.), pp. 85-115. UCLA Cotsen Institute for Archaeology, Los Angeles, CA.

GALLARDO, F., G. CABELLO, G. PIMENTEL, M. SEPÚLVEDA y L. CORNEJO. 2012. Flujos de información visual, interacción social y pinturas rupestres en el desierto de Atacama (norte de Chile). Estudios Atacameños 43: 35-52.

GIESSO, M., V. DURÁN, G. NEME, M. GLASCOCK, V. CORTEGOSO, A. GIL y L. SANHUEZA. 2011. A study of obsidian source usage in the Central Andes of Argentina and Chile. Archaeometry 53(1): 1-21.

GIL, A. F. 2006. Arqueología de La Payunia (Mendoza, Argentina). El poblamiento humano en los márgenes de la agricultura. Archaeopress, BAR International Series 1477, Oxford.

GRADIN, C. J. 1997-1998. El arte rupestre del sur Mendocino entre los siglos VIII y XV de la Era. ¿Un área de conflicto o de convivencia? Relaciones de la Sociedad Argentina de Antropología XXIIXXIII: 7-23. 
HAJDUK, A. y E. M. CÚNEO. 2009. Representaciones rupestres en la Cuenca del río Curi Leuvú (departamento Chos Malal, Provincia del Neuquén, República Argentina). Informe preliminar. EnArqueología de la Patagonia. Una mirada desde el último confín, M. Salemme, F. Santiago, M. Álvarez, E. Piana, M. Vázquez y E. Mansur(Eds.), pp. 515-526., Editorial Utopías, Ushuaia.

HARCOURT, A. H. 2012. Human Biogeography. University of California Press, Los Angeles, CA.

JONES, G. T., C. BECK, E. E. JONES y R. HUGHES. 2003. Lithic Source Use and Paleoarchaic Foraging Territories in the Great Basin. American Antiquity 68 (1): 5-38.

KELLY, R. L. 1995. The Foraging Spectrum. Diversity in Hunter-Gatherers Lifeways. Smithsonian Institution, Washington DC.

KNUDSON, K. J., W. J. PESTLE, C. TORRES-ROUFF y G. PIMENTEL. 2012. Assessing the life history of an Andean traveller through biogeochemistry: Stable and radiogenic isotope analyses of archaeological human remains from northern Chile. International Journal of Osteoarchaeology 22(4): 435-451.

LEE, R. B. 1972. !Kung spatial organization: an ecological and historical perspective. Human Ecology 1: 125-147.

LUCERO, G. 2015. Biogeografía y Paleoecología humana de tierras altas: subsistencia y tecnología en el Valle del Río de las Taguas (Departamento de Iglesia, Provincia de San Juan). Facultad de Filosofía y Letras, Universidad Nacional de Cuyo, Mendoza, Argentina. Ms.

MARQUET, P., C. SANTORO, C. LATORRE, V. STANDEN, S. ABADES, M. RIVADENEIRA, B. ARRIAZA y M. HOCHBERG. 2012. Emergence of social complexity among coastal hunter-gatherers in the Atacama Desert of northern Chile. Proceedings of the National Academy of Sciences of the United States of America 109: 14754-14760.

MCDONALD, J., 2016. Discontinuities in Australian arid zone rock art: graphic indicators for changing social complexity across space and through time. Journal of Anthropological Archaeo$\log y$. En prensa.

MCDONALD, J. y P. VETH. 2011. Information exchange among Hunter-Gatherers of the western desert of Australia. En Information and its Role in Hunter-Gatherer Bands, R. Whallon, W. Lovis y R. Hitchcock (Eds.) (Ideas, Debates, and Perspectives 5), pp. 221-233. UCLA, Cotsen Institute of Archaeology Press, Los Angeles.

MENGHIN, O. 1957. Estilos del arte rupestre de la Patagonia. Acta Praehistórica 1: 57-87.
MIZOGUCHI, K. 2009. Nodes and edges: A network approach to hierarchisation and state formation in Japan. Journal of Anthropological Archaeology 28(1): 14-26.

MYERS, F. R. 1982. Always ask: resource use and land ownership among Pintupi Aborigines of the Australian Western Desert. En Resource Managers: North American and Australian Hunter-Gatherers, N. Williams (Ed.), pp. 173-196. Westview, Boulder.

MYERS, F. R. 1986. Pintupi Country, Pintupi Self. Sentiment, Place and Politics among Western Desert Aborigines. Smithsonian Institution Press, Washington DC.

NIELSEN, A. E. 2006. Estudios internodales e interacción interregional en los Andes circumpuneños: Teoría, método y ejemplos de aplicación. En Esferas de interacción prehistóricas y fronteras nacionales modernas en los Andes sur centrales, H. Lechtman (Ed.), pp. 29-62. Instituto de Estudios Peruanos e Institute of Andean Research, New York - Lima.

NIELSEN, A. E., P. H. MERCOLLI y N. NASIF. 2010. Ocupaciones temporarias y explotación faunística en la región lacustre altoandina. En Actas del XVII Congreso Nacional de Arqueología Chilena Valdivia 2006, tomo 2, L. Adán y D. Munita (Eds.), pp. 13651378. Ediciones Kultrún, Valdivia.

NIEMEYER, H. y L. WEISNER. 1972-1973. Los petroglifos de la cordillera andina de Linares (Provincias de Talca y Linares, Chile). En Actas del VI Congreso de Arqueología Chilena, vol. II, pp. 405470. Universidad de Chile, Santiago de Chile.

O'CONNELL, J. F. 2006. How Did Modern Humans Displace Neanderthals? Insights from Hunter-Gatherer Ethnography and Archaeology. En When Neanderthals and modern humans met, N. Conard (Ed.), pp. 43-64. Tubingen Publications in Prehistory-Kerns Verlag, Tubingen.

PÁEZ, M., F. QUINTANA y C. PÉREZ. 2004. Biogeografía de las regiones áridas y semiáridas entre $35^{\circ}$ y $39^{\circ} \mathrm{S}$, Argentina. Boletín de la Sociedad Argentina de Botánica 39(3-4): 171-180.

PALLO, M. C. 2012. Análisis biogeográfico sobre el uso humano del espacio en Magallania. Tesis Doctoral, Facultad de Filosofía y Letras, Universidad de Buenos Aires. Ms.

PARUELO, J. M., A. BELTRAN, E. JOBbAGy, O. E. SALA y R. A. GOLLUSCIO. 1998. The climate of Patagonia: general patterns and control son biotic processes. Ecología Austral 8: 85-101.

PETERSON, N. y J. LONG. 1986. Australian Territorial Organization: $A$ Band Perspective. University of Sydney, Sydney. 
RE, A. 2010. Representaciones rupestres en mesetas altas de la Provincia de Santa Cruz. Circulación de información en espacios de uso estacional. Tesis de Doctorado. Universidad de Buenos Aires. MS.

REITZ, E., I. QUITMYER y D. H. THOMAS (Eds.). 2012. Seasonality and human mobility along the Georgia Bight. American Museum of Natural History, Georgia.

ROMERO, G. 2016. La clasificación de las pinturas rupestres del noreste de Neuquén, Patagonia septentrional. En Imágenes Rupestres lugares y regiones, F. Oliva, A. M. Rocchieti y F. S. Banfi (Eds.), pp. 441-452. Rosario.

ROMERO, G. y R. BARBERENA. 2015. Diseños y soportes tardíos en Patagonia septentrional. Comparación entre arte rupestre y artefactos decorados del noreste del Neuquén (Argentina). En ARKEOS 37. Symbols in the Landscape: Rock Art and its Context. Proceedings of the XIX International Rock Art Conference IFRAO 2015, H. Collado Giraldo y J. J. García Arranz (Eds.), pp. 735-742. Instituto Terra e Memória, Tomar.

ROMERO VILLANUEVA, G. y R. BARBERENA. 2016. Huesos de guanaco pintados de Cueva Huenul 1 (norte del Neuquén, Patagonia septentrional). Relaciones de la Sociedad Argentina de Antropología. Enviado.

ROMERO VILLANUEVA, G., R. BARBERENA, R. GARVEY, A. RUGHINI, C. LLANO y J. P. AGUILAR. Arqueología de Cueva Yagui (Provincia del Neuquén, Argentina). En preparación.

ROMERO, G. y A. RE. 2014. Representaciones rupestres del noreste de Neuquén (Patagonia septentrional). Primeras tendencias espaciales y temporales. Comechingonia. Revista de Arqueología 18(1): 73-92.

RUSSO, M. e I. QUITMYER. 2008. Developing Models of Settlement for the Florida Gulf Coast. En Case Studies in Environmental Archaeology, E. Reitz, C. M. Scarry y S. J. Scudder (Eds.), pp. 235254. Springer, Nueva York.

SCHEINSOHN, V. 2011. Rock Art Information among HunterGatherers in Northwest Patagonia: An Assessment of Environmental and Territorial Models. En Information and its Role in Hunter-Gatherer Bands, R. Whallon, W. Lovis y R. Hitchcock (Eds.) (Ideas, Debates, and Perspectives 5), pp. 235-247. Cotsen Institute of Archaeology Press, University of California Press, Los Angeles, CA.

SCHOBINGER, J. 1978. Nuevos lugares con arte rupestre en el extremo sur de la Provincia de Mendoza. Relaciones de la Sociedad Argentina de Antropología XII: 175-182.
SCHOBINGER, J. 2002. Arte rupestre del Departamento de Malargüe. En Entre montañas y desiertos. Arqueología del sur de Mendoza, A. Gil y G. Neme (Eds.), pp. 103-118. Sociedad Argentina de Antropología, Buenos Aires.

SCHOBINGER, J. y C. GRADIN. 1985. Cazadores de la Patagonia y Agricultores Andinos. Arte Rupestre de la Argentina. Encuentro Ediciones, Madrid.

SEELENFREUND, A., C. REES, R. BIRD, G. BAILEY, R. BÁRCENA y V. DURÁN. 1996. Trace element analysis of obsidian sources and artifacts of Central Chile (Maule River Basin) and Western Argentina (Colorado River). Latin American Antiquity 7: 7-20.

SHACKLEY, M. S. 2005. Obsidian: Geology and Archaeology in the North American Southwest. The University of Arizona Press, Tucson, AZ.

SHEA, J. M., B. MENOUNOS, R. D. MOORE y C. TENNANT. 2013. An approach to derive regional snow lines and glacier mass change from MODIS Imagery, Western North America. The Cryosphere 7: 667-680.

STANNER, W. E. H. 1965. Aboriginal Territorial Organization: Estate, Range, Domain and Regime. Oceania XXXVI(1): 1-26.

STERN, C. R. 2004. Active Andean volcanism: its geologic and tectonic setting. Revista Geológica de Chile 31(2): 161-206.

TORRES-ROUFF, C., G. PIMENTEL y M. UGARTE. 2012. ¿Quiénes viajaban?: Investigando la muerte de viajeros prehispánicos en el Desierto de Atacama (ca.800 AC-1536 DC). Estudios Atacameños 43: 167-186.

VARGAS, F. E. 2015. Petroglifos del Norte Neuquino en la cuenca del CuriLeuvú. Un abordaje desde la Arqueología del Paisaje. Tesis de Licenciatura. Universidad Nacional de Rosario. Ms.

VEGA, T. 2016. El arte rupestre del norte neuquino. Las formas y sus valores. En Libro de Resúmenes Segundo Congreso Nacional de Arte Rupestre, A. M. Rocchietti et al. (Eds.), pp. 13-14. Laboratorio de Arqueología y Etnohistoria, Departamento de Historia, Facultad de Ciencias Humanas, Universidad Nacional de Río Cuarto, Rosario.

VEGA, T., M. GELÓS, P. BESTARD y C. MARZARI. 2007. Patrimonio cultural, arqueológico e histórico: uso y preservación. En Debates actuales en Arqueología y Etnohistoria. Publicación de las $V y$ VI Jornadas de Investigadores en Arqueología y Etnohistoria del CentroOeste del País, E. Olmedo y F. Ribero (Comps.), pp. 317-331. Universidad Nacional de Río Cuarto, Río Cuarto. 
VEGA, T., M. B. GELÓS y P. BESTARD. 2016. Gestión del arte rupestre neuquino. Caso Parque Arqueológico Colomichicó. En Imágenes Rupestres lugares y regiones, F. Oliva, A. M. Rocchieti y F. S. Banfi (Eds.), pp. 415-422. Rosario. ISBN: 978-987-42-2799-7.

VERGARA DUPLAQUET, C. 1972-1973. Petroglifos de las piedras de las marcas. En Actas del VI Congreso de Arqueología Chilena, vol. II, pp. 471-485. Universidad de Chile, Santiago de Chile.

WHALLON, R. 2006. Social networks and information: Non "utilitarian" mobility among hunther-gatherers. Journal of Anthropological Archaeology 25 (2): 259-270.

WHALLON, R. 2011. An introduction to information and its role in hunter-gatherer bands. En Information and its Role in Hunter-Gatherer Bands, R. Whallon, W. Lovis y R. Hitchcock (Eds.), pp. 1-27 (Ideas,
Debates, and Perspectives 5). Cotsen Institute of Archaeology Press, University of California Press, Los Angeles, CA.

WHEATLEY, D. y M. GILLINGS. 2002. Spatial technology and archaeology. The archaeological applications of GIS. Taylor \& Francis, Londres.

WOBST, M. 1977. Stylistic behavior and information exchange. En For the director: research essays in honor of James B. Griffin, C. E. Cleland (Ed.), pp. 317-342. University of Michigan, Ann Arbor.

YACOBACCIO, H. D. 1994. Biomasa animal y consumo en el Pleistoceno-Holoceno Surandino. Arqueología 4: 43-71. 